\title{
VERSITA
}

\section{Comparing Survey and Sampling Methods for Reaching Sexual Minority Individuals in Flanders}

\author{
Alexis Dewaele ${ }^{1}$, Maya Caen ${ }^{2}$, and Ann Buysse ${ }^{1}$
}

\begin{abstract}
As part of a large sexual health study, we used two different approaches to target Sexual Minority Individuals (SMIs). Firstly, we drew on a probability sample (1,832 respondents aged 14-80) of the Flemish population in Belgium. Secondly, we set up a targeted sampling design followed by an Internet survey. Our focus was to explore how two different sampling procedures and survey designs could lead to differences in sample characteristics. Results showed that for female SMIs (we excluded male SMIs from the analyses due to their low numbers) the population sample differed from the Internet sample in terms of sociodemographic characteristics (the latter included younger and more highly educated respondents) and scores on sexual orientation dimensions (the population sample included more respondents who didn't identify as lesbian or bisexual but reported same-sex sexual experiences and desire). Respondents' scores on sexual health indicators differed between the samples for two of the seven variables. We discuss implications for improving the quality and validity of nonrandom samples.
\end{abstract}

Key words: Hard-to-reach populations; self-selection bias; nonrandom samples.

\section{Introduction}

Lesbian women, gay men and bisexuals (LGBs) are widely considered a hard-to-reach population. As part of a larger systematic study of sexual health, we used two different approaches to target this population. In our national sample, we drew on a probability sample (1,832 respondents aged 14-80) of the Flemish population (the Dutch-speaking community in Belgium) based on the Belgian National Register. For the other arm of the study we set up a targeted sampling design followed by an Internet survey, using a nearidentical questionnaire. By identifying a population of sexual minority individuals (we prefer using the acronym SMI instead of LGB since the latter implies self-identification; SMI also refers to individuals who do not identify as LGB but who have or have had samesex partners) in the national survey, we explored how two different sampling procedures

${ }^{1}$ Faculty of Psychology and Educational Sciences, Department of Experimental Clinical and Health Psychology, Ghent University, B-9000, Ghent, Belgium. Email: Alexis.dewaele@ugent.be

${ }^{2}$ Department of Sociology, Research team CuDOS, Ghent University, B-9000, Ghent, Belgium.

Acknowledgments: The Sexpert study group includes Ann Buysse (Ghent University: Department of Experimental, Clinical and Health Psychology), Paul Enzlin (KU Leuven: Department of Development and Regeneration, Institute for Family and Sexuality Studies and UPC KU Leuven, Context - Centre for Couple, Family and Sex Therapy), Guy T’Sjoen (Ghent University Hospital: Department of Endocrinology and Center for Sexology and Gender Problems), John Lievens, Mieke Van Houtte and Hans Vermeersch (Ghent University: Department of Sociology, Research Team Cultural Diversity: Opportunities and Socialisation). The Sexpert study was funded by the Strategic Basic Research program of the Flemish Agency for Innovation by Science and Technology. 
and survey designs led to differences in sample characteristics, especially where sexual health and sociodemographic characteristics are concerned. Hence, we provide insight into self-selection processes and explore future strategies for improving the quality and validity of nonrandom samples that rely upon self-selection. This validation, through comparison of data collected by different sampling methods, is especially useful when referring to survey data for program and policy development (Schwarcz et al. 2007). In this study, we took the unique opportunity to compare two datasets from a larger sexual health study in Flanders, Belgium. Due to the low numbers of male SMIs in our population sample, we only focused on female SMIs.

\subsection{Gathering Data on Sexual Minority Individuals Through Probability and Nonprobability Samples}

Gathering a population-based probability sample while including multidimensional and continuous measures for sexual orientation guarantees that respondents from diverse age groups, levels of education, geographical locations, and, presumably, also with different sexual orientations are covered (see e.g., Laumann et al. 1994; Bajos and Bozon 2008). However, the proportions of men and women who identify as nonheterosexual in population-based probability surveys are often small (Rothblum 2007). The low proportions of SMIs are particularly troublesome as small (absolute) numbers lead to difficulties in estimating reliable parameters. This is especially true for communities such as Flanders (the northern, Dutch-speaking part of Belgium, which has about 6 million inhabitants), where high-quality, population-based representative surveys via face-to-face interviews, typically with samples drawn from the National Register, are not only very expensive in terms of sampling procedures but also require enormous resources (in terms of workforce, time and general effort) in order to organize and carry out data collection. Secondly, researchers have used self-identity, sexual activity and cohabiting status as ways to find nonheterosexual respondents. However, these dimensions are usually not highly correlated. For example, in census data the gender of partners who are cohabiting is sometimes used to capture SMIs. This of course leaves out information about those who are single and those who are not living with their partner (Rothblum 2007). All of these problems can be addressed in Internet surveys.

Making the questionnaire available on the Internet through Computer Assisted Self Interviewing (CASI) has several advantages (see e.g., Wright 2005; Evans and Mathur 2005; Couper 2008). It is a relatively cheap and fast way to gather data (Best and Krueger 2004; Heerwegh 2001). For the SMI target group in particular, it offers a highly accessible and anonymous way of posing delicate questions and gathering information about private matters (Bauermeister et al. 2012). Administration of a questionnaire through the Internet can increase the level of reporting of sensitive information and has a positive effect on accuracy (Kreuter et al. 2008; Tourangeau et al. 2003). Some authors also refer to high rates of Internet use by (young) SMIs because this medium offers them opportunities to find peers (Silenzio et al. 2009).

The most obvious drawback of Internet surveys is that they may not be representative of the population of interest because the subpopulation with access to the Internet may be quite specific (i.e., coverage error) (Couper 2000; Schonlau et al. 2009). Moreover, 
Internet surveys typically rely upon self-selection and thus tend to reach respondents with a particular interest in the survey's topic (Couper 2000). On the other hand, intrinsic interest in the survey's topic to some level determines respondents' willingness to participate in other surveys (for instance face-to-face surveys) as well (e.g., Groves et al. 2006). To evaluate potential coverage error and self-selection bias, it is important to compare Internet and offline methods.

\subsection{Comparing Internet and Offline Methods for Reaching SMIs}

Very few studies have involved a research design that allows direct comparison of (near-) identical questionnaires, assessed via highly comparable administration modes, but following different sampling procedures (see e.g., Denscombe 2006). Moreover, results from existing analyses have often proven inconsistent (de Leeuw 2005).

Schillewaert and Meulemeester (2005) compared four different methods of data collection in Flanders, both offline (through a mail survey and random digit dialing) and online (through pop-ups on high traffic sites that linked to the survey and via an Internet web panel) using identical questionnaires. Differences in sociodemographic characteristics appeared widespread across both offline and online methods. Subjects in the online pop-up sample seemed to be more extroverted and outgoing, while the mail sample showed a more traditional and introverted profile. After adjusting the weight of gender and age to match national population distributions, and after randomly reselecting observations such that they no longer differed from the national population, no major differences were found between the four recruitment methods in terms of demographics and attitudes, interests and opinions. The authors concluded that for traditional research topics, online research tools are at least as externally valid as research conducted via traditional methods.

Other researchers have compared Internet-based and venue-based methods to contact and survey male SMIs. Time location sampling at venues, Internet forum-based sampling and direct marketing (placing banner advertisements on online forums frequented by male SMIs) produced samples that showed variation in terms of residence location, age, income, and self-reported HIV status, as well as prevalence of substance use, methamphetamine use, and serodiscordant partnerships. The direct marketing approaches (i.e., placing banner ads on high traffic [gay and nongay] websites) were more passive in nature and it was therefore suggested that these techniques might result in the recruitment of fewer men who engage in high-risk behaviors in comparison with more active approaches (Raymond et al. 2010). Koch and Emrey (2001) found that a sample of gay men and lesbians recruited through the Internet showed similar characteristics to a national sample of gay men and lesbians. They compared demographic data (education, income, age, race, party identification, and ideology) collected from over 10,000 gay and lesbian users of a single website with data from a sample of national voters: the 1992 Voter Research and Surveys exit poll (Edelman 1993). This national survey included information about voters' sexual orientation, thus providing a useful comparison. Although some differences were found (e.g., the Internet sample was younger), the overall distribution of responses on these demographic variables across the two samples tended to be similar.

Finally, Fernee and Keuzenkamp (2011) compared two samples with respondents who identified as SMIs. The first was a sample containing SMIs recruited through the Internet, 
social networks, social media, SMI- and non-SMI specific media $(N=5,069)$. Most respondents were recruited through lesbian- or gay-specific channels or by word of mouth through lesbian or gay friends/acquaintances. The second sample included randomly recruited SMIs from a large Internet panel. Neither sample was representative of the population in the Netherlands, despite the fact that the respondents from the Internet panel did not volunteer themselves. When age and gender differences were controlled for, the first sample, i.e., the group of self-selected respondents, was found to include significantly more exclusively gay/lesbian versus bisexual respondents, as well as more respondents who were open about their sexual orientation. The authors evaluated the data from the Internet panel as more reliable than the data from the sample with self-selected respondents (Fernee and Keuzenkamp 2011). To conclude, it seems that some studies comparing different sampling methods have uncovered different sample characteristics. Other studies have found comparable samples from different sampling methods with or without controlling for sociodemographic variables.

Face-to-face CASI and web-based CASI both address the problem of interviewer effects on disclosure by SMIs. An Internet survey has the additional advantage that much larger datasets can be obtained in order to avoid unreliable parameter estimates related to small sample sizes. Internet surveys are also far less expensive than populationbased probability samples, which typically entail high sampling and data collection costs. Some research shows that results from Internet surveys are comparable to results from traditional methods once differences in sociodemographic sample characteristics are controlled for. Other studies have pointed out that significant differences related to sexual health indicators or minority characteristics (e.g., type of self-identification, openness about one's sexual orientation) remain. In this article we investigate differences in sociodemographic variables, dimensions of sexual orientation, and sexual health indicators between a representative sample and a nonrepresentative (Internet) sample of SMIs.

\section{Research Design and Methods}

\subsection{Research Procedure}

The first study draws on data from the survey 'Sexual Health in Flanders' (Buysse et al. 2013). Respondents (between 14 and 80 years of age) were randomly drawn from the Belgian National Register. In order to enhance statistical power in each of the three predefined age categories we used a stratified sample, meaning that one third of the sample consisted of the youngest responders (aged 14 to 25), one third of the middle age group (aged 26 to 49) and one third of the oldest group (50 to 80 years old). Elaborate contact procedures following Dillman's Total Design Method (Dillman 1978; 2000) were used to maximize the cooperation, the (item) response rate and the quality of all the survey measures. Moreover, some refusal conversion techniques (e.g., a second contact attempt after an initial refusal, made by a different interviewer) were applied. Data were collected between February 2011 and January 2012, and the final database consisted of 1,832 respondents, 125 of whom can be identified as SMIs (response rate: $40.0 \%$ of the eligible respondents). After data collection, the data were weighted by gender, age, and schooling level in order to make them representative of the population of Flanders aged 14-80. This enabled us to 
partially correct for higher nonresponse rates, which were found for older age groups and among those with a lower educational level.

All data were gathered via face-to-face interviews, using a combination of computerassisted personal interviewing (CAPI) and computer-assisted self-interviewing (CASI). To elaborate, all sensitive information, that is, a wide range of sexual health indicators, was gathered in a CASI set-up, so that respondents never had to share private information about their sexual health with an interviewer. In this study we only used the data related to sexual health that were gathered in the CASI mode.

While we acknowledge that a response rate of $40 \%$ is somewhat lower than expected, especially when compared with other population-based probability surveys, very similar response rates have been found in other European, population-based surveys of sexual health and/or sexual behavior, such as a study in Finland (response rate of 46\%), or another conducted in Estonia and Saint Petersburg (response rate of 41\%) (Gronow et al.1997; Haavio-Mannila and Kontula 2001). Moreover, both the sensitivity of the survey's topic needs to be taken into consideration as well as its extent, that is, the wide range of sexual and general health indicators and the wide range of correlates covered, and consequently, the duration of the interview (80 minutes on average). Moreover, the poststratification weightings mentioned above ensured that we could, at least to some degree, adjust for higher nonresponse/refusal rates in specific sample groups.

The second study draws on data from the survey 'Click out of the bed room', a large-scale nonrepresentative survey on sexuality, sexual health and relations in SMIs in Flanders. As it was important to recruit all SMIs, including those who do not self-identify as gay, lesbian or bisexual, we set up a neutral as well as an LGB-oriented campaign. The neutral campaign refers to 10,000 posters utilizing an image that did not specifically refer to being lesbian, gay or bisexual that we distributed all over Flanders. The message on the poster presented the survey as related to sexual health in general. Banners, adverts on the Internet and press releases including this neutral image and message were also produced and circulated.

In addition, we also set up a recruitment strategy to target SMIs. To attract a relatively diverse sample we used a variety of recruitment channels and methods. We have learned from previous research that older LGBs, bisexuals, and LGBs with low levels of education are particularly difficult to reach for research purposes (Vincke and Stevens 1999). Additionally, using LGB associations to recruit potential respondents may lead to a large selection bias (see Vincke and Bleys 2003; Vincke and van Heeringen 2004). Our sample strategy was therefore oriented towards avoiding both bias and a lack of representation of specific groups.

We used the following recruitment channels to broadcast a request for respondents: specific locations such as LGB discotheques, LGB parties and LGB events; advertisements in the written press; LGB-specific and non-LGB-specific associations and organizations were invited to spread the invitation; electronic mailings were sent and the Internet was used (e.g., banners posted on LGB-specific websites). We paid for banners on two high traffic sites. The first, GayBelgium, is the largest LGB-specific website in Flanders. The second, 'Seniorennet', targets Internet users older than 50 years. A snowball method was used to recruit respondents through acquaintances, friends, family members, and so forth. Respondents who entered the survey website (www.klikeensuitbed.be) or who finished the survey could invite a friend to participate. A promotional team (including 
some of the researchers) distributed posters, flyers, and gadgets (small mint tins) that included the URL throughout all Flemish provinces, in large and small towns and villages. The team visited LGB-specific events and activities (parties, a LGBT film festival, LGBT bars) but also put in an extra effort to reach female and elderly SMIs at specific activities. Postal packages (containing posters, flyers and gadgets) were sent out to roughly 180 LGB-specific (bars, shops, associations) and 50 non-LGB-specific (including libraries, cafés, and public health centers) addresses. Key persons within LGBT associations and sexual health organizations were also approached to help us to get in contact with potential respondents through mailings and posts or banners on websites. Finally, a Facebook campaign was set up to recruit respondents. A Facebook panel was integrated into the survey website so that visitors or respondents could 'like' our Facebook page. People who 'liked' our Facebook page received posts about the progress of the research project. Friends of people who 'liked' our Facebook page were indirectly introduced to the project. Finally, we contacted several well-known LGBs who were invited to 'become friends' with the Facebook page and to post promotional messages on their Facebook walls.

Out of the total number of respondents, $35.4 \%$ found our site through a social network site (mainly Facebook), 18.5\% through an electronic mailing, 15.3\% through television, radio, a newspaper or a magazine, $10.6 \%$ through clicking on a banner on a website, $6.7 \%$ through their school or work, 3.7\% through a gadget or flyer, $2.2 \%$ through an association or activity, $1.7 \%$ through a poster, and $5.8 \%$ through other means. Data were collected between September 2011 and March 2012. The final database consisted of 3,702 respondents, 2,468 of whom were identified as SMIs. Respondents between 13 and 86 years of age were included. At the beginning of the survey postal code of the respondents' current place of residence was registered. Respondents living in provinces outside of Flanders were removed from the dataset.

Table 1 summarizes the sampling frames and designs, the differences in (estimated) coverage of the frame, the different sampling methods, and the different contact/recruitment procedures applied in both surveys. The questionnaire used in the internet survey is similar to the first study but significantly shorter to address respondent drop out. More specifically, it only contains the questions on sexual health indicators, administered by CASI (see also Table 2 for a thorough comparison of the question wording and modes of administration).

\subsection{Measures}

We will refer to the population sample and to the Internet sample in turn. Firstly, we will elaborate on how we identified SMIs in both samples. Next, we will present an overview of sexual health measures.

In this study, we took different dimensions of sexual orientation (self-identification, sexual behavior and sexual desire, see also below) into account to construct a group of SMIs. Doing so yielded a larger proportion of female SMIs $(9.8 \%, N=90)$ compared to male SMIs $(3.9 \%, N=35)$. This is due to the fact that the women in our study reported more same-sex sexual desire than men. This is in line with other studies, which have shown that a higher proportion of women than men report same-sex attraction (Bajos and Bozon 2008), or report same-sex attraction without identifying as gay, lesbian, or bisexual (Laumann et al. 1994; Roberts et al. 2010). Unfortunately, in our case this meant that we 


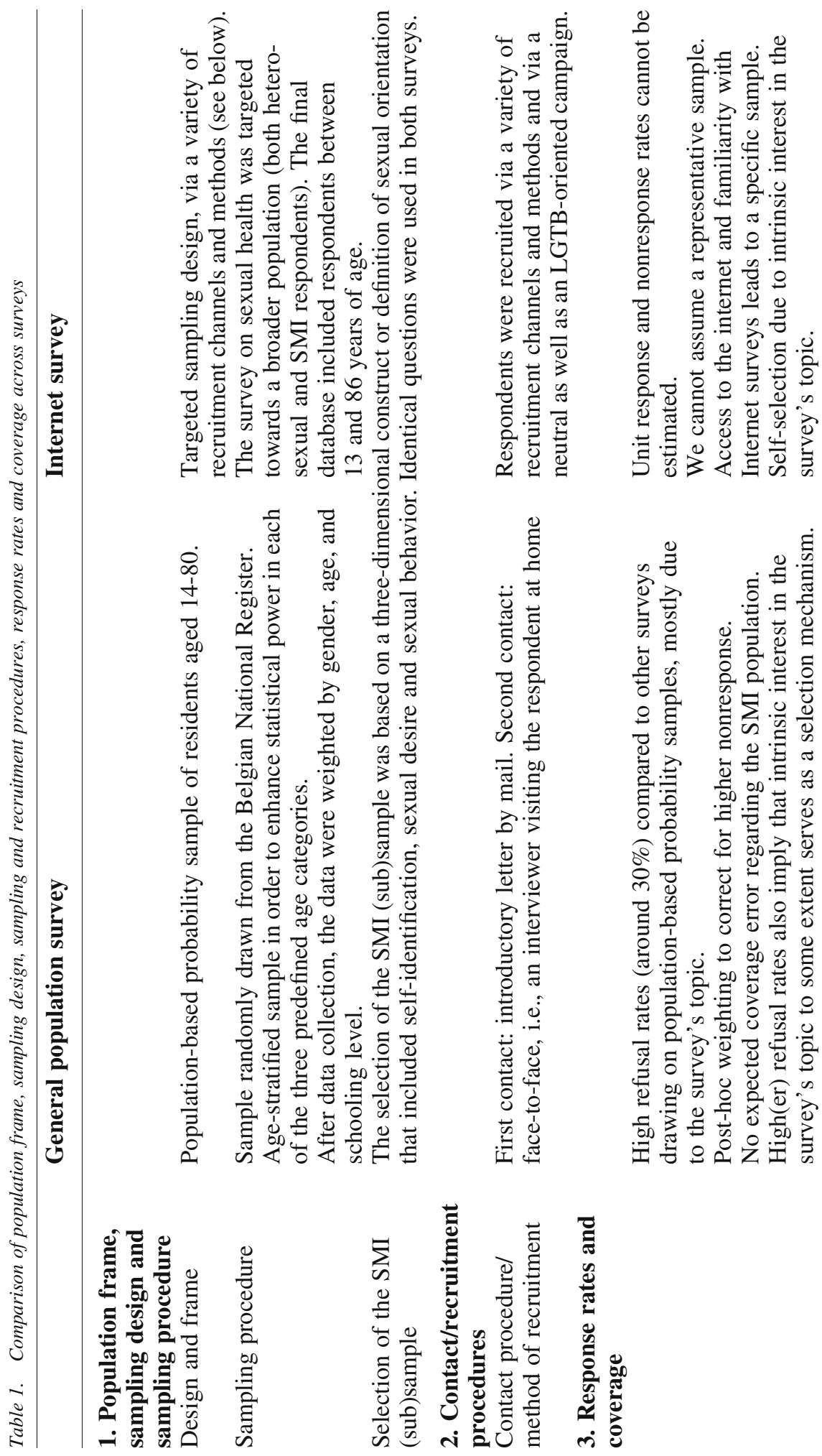




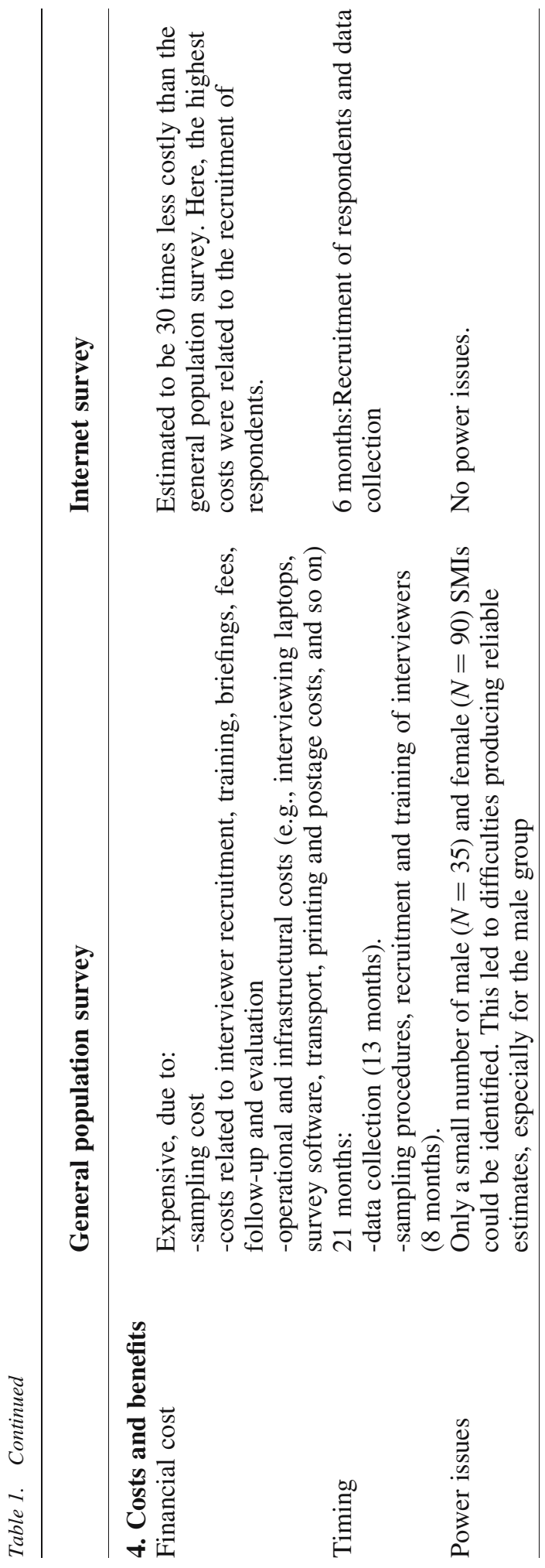




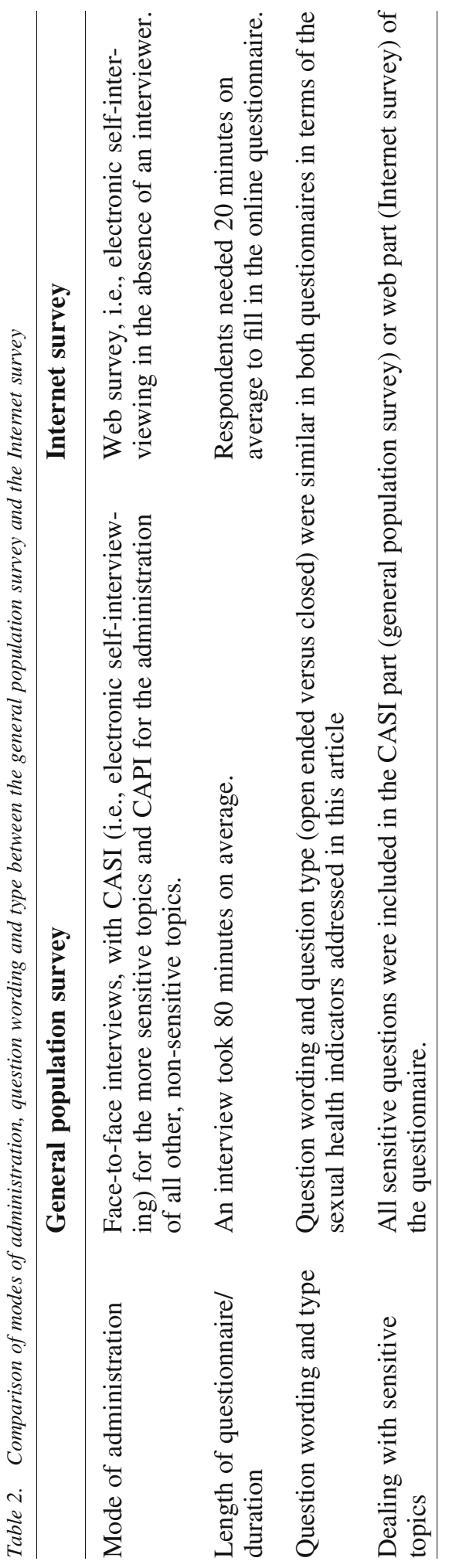


could only work with the data gathered from the female group, as the smaller male group would not have produced reliable estimates.

Sexual orientation. In order to accurately assess the number of SMIs in each of the samples, we needed a clear definition of sexual orientation. It was deemed important to use a definition of sexual orientation that was neither too restricted nor too broad. From a sexual health perspective, for instance, this definition also had to include women who have sex with women but who do not identify as lesbian or bisexual (see e.g., Mercer et al. 2007; Kerker et al. 2006; Van Kesteren et al. 2007).

We conceptualized sexual orientation as a three-dimensional construct measuring self-identification, sexual behavior and sexual desire (cf. Laumann et al. 1994). Sexual selfidentification was assessed with the question: "How would you identify yourself?" Respondents could answer on a 5-point Likert scale (i.e., straight, more straight than gay/ lesbian, bisexual, more gay/lesbian than straight, gay/lesbian). An open-ended response category was added for respondents who did not identify with any of these labels (referred to as other). To measure sexual behavior, we first asked respondents: "Throughout your life, how many people have you had sex with?" (categorical open-ended numeric answer). Then we asked: "Were these people men, women or both?" Respondents could answer on a 5 -point Likert scale (from $1=$ only women to $5=$ only men). We used two items to measure the dimension of sexual desire. We asked respondents: "Do you sexually fantasize about men, women or both?" and "Do you feel sexually attracted to men, women or both?" In both cases, respondents could answer on a 5-point Likert scale (from $1=$ only about or only attracted to women to $5=$ only about or only attracted to men). Respondents could also answer these questions with "I fantasize about or I am attracted to neither". With the information gathered from these four items, measuring three dimensions, we created one dichotomous variable categorizing respondents as SMI (i.e., '0') or heterosexual (i.e., '1'). They were identified as SMI when they reported identifying as gay/ lesbian, bisexual or more gay/lesbian than straight, or when they reported having at least as many same-sex sexual fantasies as opposite-sex fantasies, or when they reported to feel at least as often attracted to the same sex as to the opposite sex, or when they reported having had at least as many same-sex sexual contacts as opposite-sex sexual contacts.

Indicators of sexual health. We explored seven indicators of sexual health to gain insight into the differences or similarities in sexual health outcomes between SMIs drawn from the population sample and those from the Internet sample. As some indicators of sexual health are only relevant to sexually experienced respondents (i.e., respondents who have had sex), for five out of seven variables the analyses were restricted to sexually experienced SMIs from both samples. We first discuss these five indicators (number of sexual partners, age at first sexual experience, frequency of sexual activity, perceived satisfaction, and importance of sex), followed by two indicators concerning experiences of sexual abuse.

The number of sexual partners was measured by means of a question that required a categorical open numeric answer. We asked sexually experienced respondents: "Throughout your life, how many people have you had sex with?" We defined sex as "all ways of making love involving genital contact. We do not only refer to sexual intercourse”. Because of the skewed distribution, we recoded this variable to six categories (one partner, 2 to 3 partners, 4 to 5 partners, 6 to 9 partners, 10 to 19 partners, or 20 or more partners). 
Secondly, the age at first sexual experience or intercourse was probed with a categorical open numeric answer. We asked respondents: "How old were you when you had your first sexual experience or the first time you had sexual intercourse?" As a third indicator of sexual health, frequency of sexual activity was measured with an open numeric answer category. We asked respondents: "In the past two weeks, how often did you have sex?" Again, we defined sex as detailed above. Because of a skewed distribution, we recoded this variable to four categories (less than 0.5 times, 0.5 to 1.99 times, 2 to 4 times or more than 4 times in two weeks). The fourth and fifth indicators - perceived satisfaction and importance of sex - were each measured on a 5-point Likert scale (from very dissatisfied/unimportant to very satisfied/important).

Next, we presented two questions that assessed experiences of sexual abuse. We modified items from a large-scale population-based study on sexual health in the Netherlands (Bakker et al. 2009). Belgian law does not permit us to assess sexual abuse in minors without reporting any incidents to the authorities, meaning we would have had to violate the anonymity of respondents. Therefore, we choose to present these items only to respondents aged at least 18 years at the time of the survey. These final two indicators summarize information from the following items: "Has someone forced you to masturbate against your will?" (yes/no), "Has someone forced you to undergo or perform oral sex against your will?"(yes/no), "Has someone tried to rape you?” (yes/no) and "Has someone raped you?" (yes/no). For all four items, the question was split up in order to separate experiences before the age of 18 from experiences after the age of 18 . Respondents who reported 'yes' on at least one of the aforementioned items were considered to have experienced sexual abuse. With this information, we created two dichotomous variables categorizing respondents as those who had or had not experienced sexual abuse, before or after the age of 18 .

\section{Results}

Firstly, we compare the sociodemographic composition of both samples through binomial regression analyses. Secondly, as it is important to include WSW (i.e., women who have sex with women but who do not identify as lesbian or bisexual) in the sample, we focus on differences in the relationships between dimensions of sexual orientation. We will compare the proportion of respondents who reported 'same-sex' on one or several dimensions (i.e., sexual desire, behavior, or identity) related to sexual orientation. Thirdly, we use the 'dataset' (population survey versus Internet survey) as a predictor for sexual health indicators. These results can be used to deduce whether scores on sexual health indicators differ significantly between female SMIs in the population sample and the Internet sample. Finally, we explore the differences between the datasets found in the third step, this time controlling for age, level of education, occupational category, subjective evaluation of income, family situation, and existence of a current romantic relationship (see Table 3 for descriptive statistics).

\subsection{Differences in Sociodemographic Composition of the Samples}

A broad range of respondent characteristics, available in both surveys, were included in a stepwise binomial logistic regression with sample membership as the dichotomous 


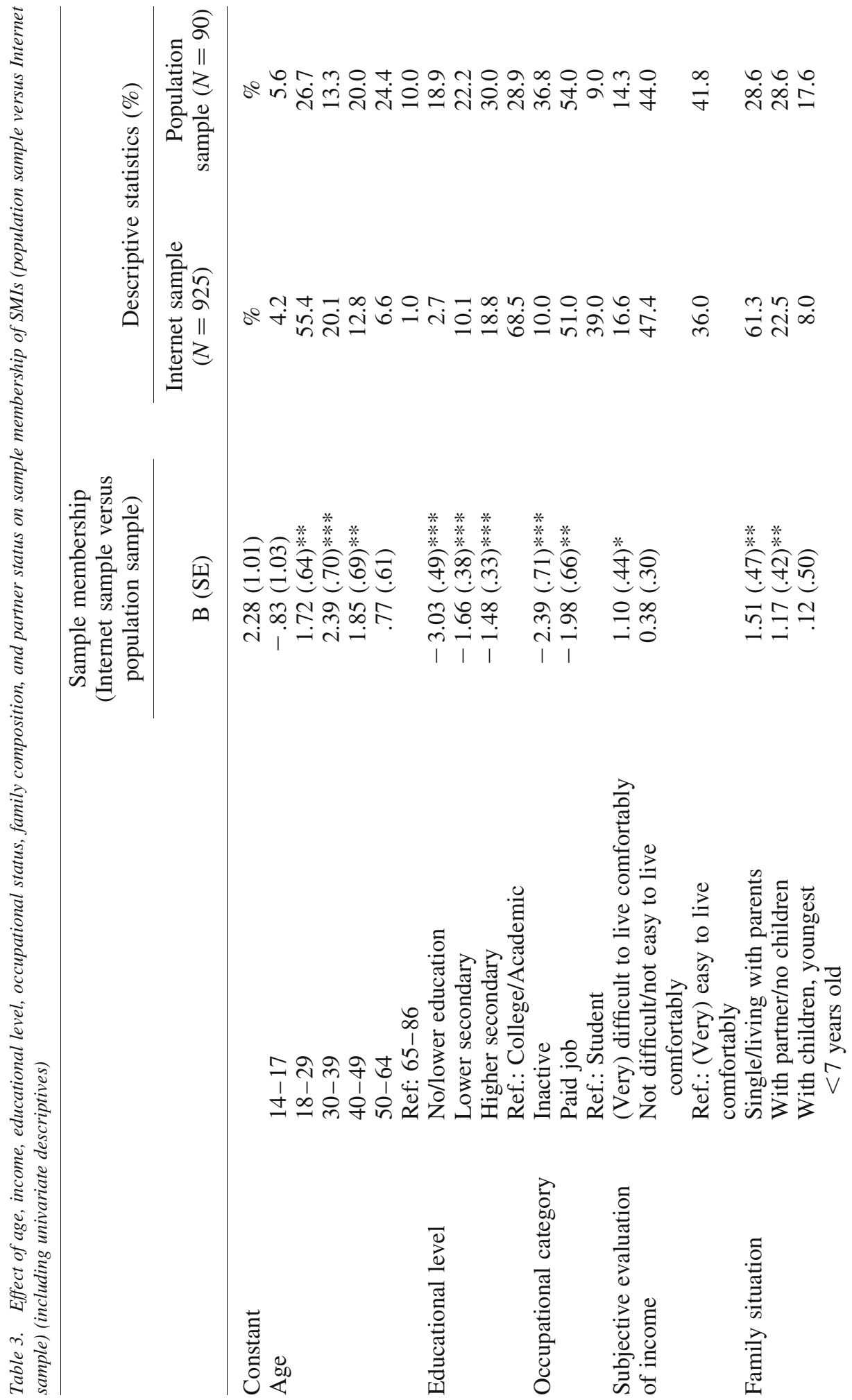




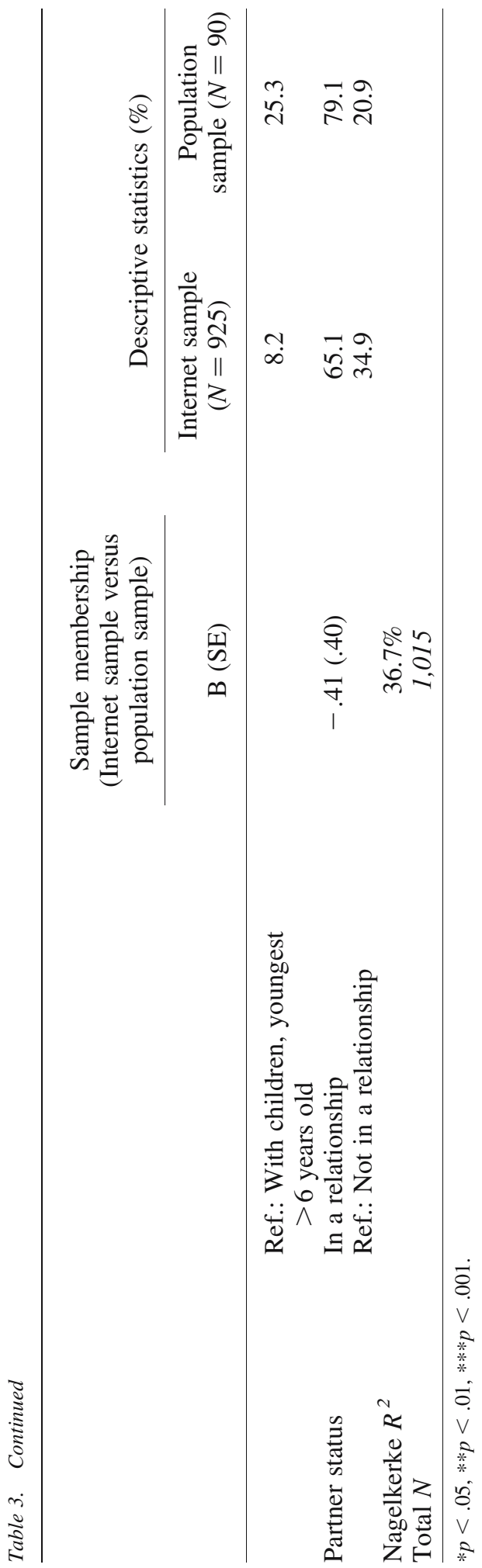


independent variable (population versus Internet sample). This enabled us to infer which covariates were the most likely explanations of differences in specific survey outcomes (e.g., differences between sexual health indicators). This analysis showed age, educational level, occupational category and income to be the most important correlates (Table 3). However, these four indicators only explain about one third of the variance, indicating that a lot of the explanatory factors and distinct features of self-selection and different sampling techniques remain to be explored.

\subsection{Differences in Relationships Between Dimensions of Sexual Orientation}

Because the three dimensions of sexual orientation (same-sex desire, behavior, and identity) may or may not overlap, and because this is relevant from a sexual health perspective, it is important to explore differences in the number of respondents within these intersections in both samples. Therefore, we tested whether scores on each of these combined dimensions significantly differed between the population and the Internet sample (see Figures 1 and 2).

Due to the relatively low number of female SMIs in the population sample $(N=90)$, we were unable to compare every score on a specific dimension (or intersection between dimensions) between the samples. In the population sample, $60.3 \%$ of the SMI respondents reported same-sex desire and behavior without identifying as lesbian or bisexual (LB), compared to $8.2 \%$ of the respondents in the Internet sample $(p<.001)$. In the Internet sample $59 \%$ of the respondents reported same-sex desire, behavior, and identified as LB, compared to $23.9 \%$ of the respondents in the population sample $(p<.001)$. In the Internet sample we found a significant proportion $(31.4 \%, N=290)$ of respondents who reported same-sex desire and identified as LB without reporting

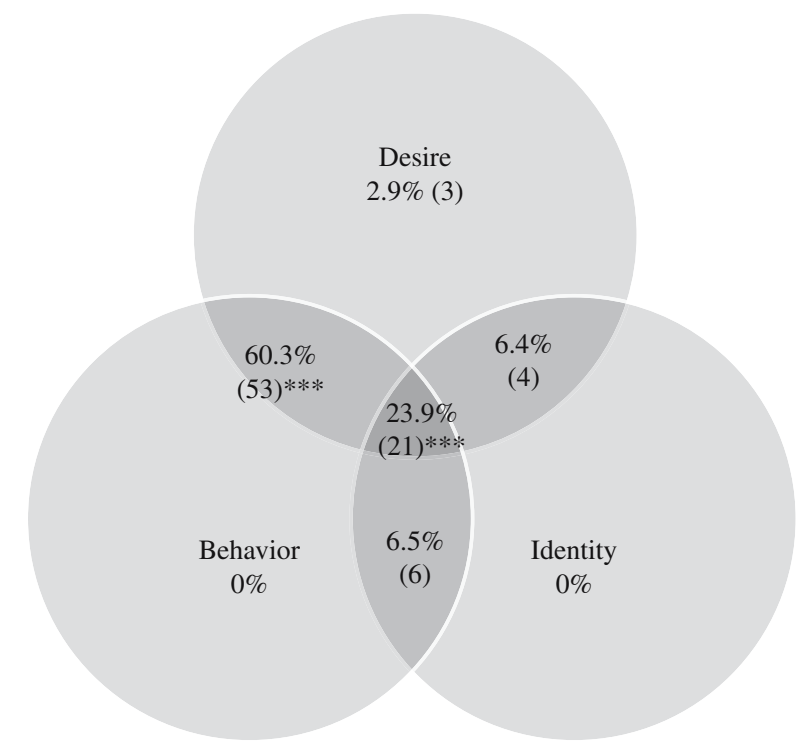

Fig. 1. Relationships between dimensions of sexual orientation in the population sample $(N=88)$ (tested differences between the population sample and the Internet sample). $* * * P<.001$ 


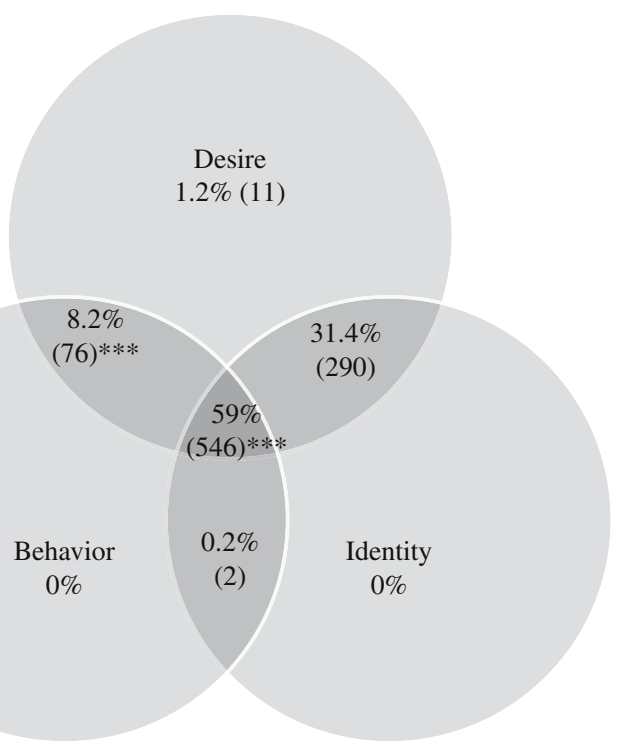

Fig. 2. Relationships between dimensions of sexual orientation in the Internet sample $(N=925)($ tested differences between the population sample and the Internet sample). $* * * P<.001$

same-sex behavior. This was not the case in the population sample $(6.4 \%, N=6)$. We conducted a binary logistic regression with age, dataset, and educational level as independent variables, and sexual orientation $(1=$ same-sex desire, identifying as LB but without same-sex behavior, $0=$ all other categories) as a dichotomous dependent variable (see Table 4). Respondents in the age category 18 to 29 years old reported more same-sex desire while identifying as LB but without same-sex behavior than respondents

Table 4. Predictors of same-sex desire and identity without same-sex behavior

\begin{tabular}{lc}
\hline Variable & $\mathrm{B}(\mathrm{SE})$ \\
\hline Constant & $-3.43(.55)^{* * * *}$ \\
Dataset & $-1.71(.47)^{* * * *}$ \\
$\quad$ Population survey & \\
Ref.: Internet survey & $.12(.42)$ \\
Educational level & $-.35(.26)$ \\
$\quad$ No/lower education & $.27(.18)$ \\
$\quad$ Lower secondary & \\
$\quad$ Higher secondary & \\
Ref.: College/Academic & $1.22(.33)^{* * *}$ \\
Age & $.44(.37)$ \\
$\quad 18-29$ & $.39(.39)$ \\
$30-39$ & $.10 * * *$ \\
$\quad 40-49$ & 1,026 \\
Ref: $50-86$ & \\
Nagelkerke $R^{2}$ & \\
$N$ &
\end{tabular}


Table 5. Predictors of same-sex desire and behavior without identity

\begin{tabular}{lc}
\hline Variable & $\mathrm{B}(\mathrm{SE})$ \\
\hline Constant & $1.86(.43)^{* * * *}$ \\
Dataset & $3.38(.36)^{* * * *}$ \\
$\quad$ Population survey & \\
Ref.: Internet survey & \\
Educational level & $-1.41(.62)^{*}$ \\
$\quad$ None/primary education & $-68(.39)$ \\
$\quad$ Lower secondary & $-.47(.32)$ \\
$\quad$ Higher secondary & \\
Ref.: College/Academic & \\
Age & $-.03(35)$ \\
$\quad 18-29$ & $-1.38(.46) * *$ \\
$\quad 30-39$ & $-.71(.43)$ \\
$\quad 40-49$ & $.31 * * *$ \\
Ref: $50-86$ & 691 \\
Nagelkerke $R^{2}$ & \\
$N$ &
\end{tabular}

in the age category 50 to 86 years old. This at least partly explains the larger number of LBs with same-sex desire but without same-sex behavior in the Internet sample, since this survey included a larger group of young respondents.

The descriptive statistics mentioned above might be misleading due to different sample characteristics related to the educational level and age of respondents. To control for these different sample characteristics, we conducted a binary logistic regression (see Table 5). We created a dichotomous variable for the dependent variable. Scores of ' 1 ' and ' 0 ' respectively referred to women who reported same-sex desire and behavior without identifying as LB, and to women who report same-sex desire, behavior, and identified as LB. All scores related to the other categories were treated as missing values. This analysis showed that, when educational level and age were controlled for, respondents in the Internet sample were still less likely to report same-sex desire and behavior without identifying as LB than respondents in the population sample.

\subsection{The Dataset As a Predictor for Sexual Health Indicators}

To compare scores on sexual health indicators, we merged the two datasets. We found that the datasets only differed on one of the seven sexual health indicators (see Table 6). Furthermore, stepwise multivariate analyses (with dataset included in a first model, and dataset and sociodemographic variables included in a second model) showed that for five of the seven sexual health indicators (sex frequency, sexual satisfaction, importance of sex and experience with sexual abuse before or after the age of 18), there were no differences in scores between the datasets, independent of whether or not we added sociodemographic variables to the model (these tables have not been included in this article).

Regarding 'Number of (lifelong) sexual partners' (Table 7), we found that controlling for age, and especially for educational level, alters the initial difference found between 
Table 6. Differences in survey measures (Internet survey versus population survey) for seven sexual health indicators

\begin{tabular}{lcc}
\hline & Internet survey & Population survey \\
$N$ (only sexually experienced respondents) & 870 & 84 \\
\hline Number of lifelong sex partners & & \\
1 & $11.2 \% * * *$ & $25.6 \% * * *$ \\
$2-3$ & $23.1 \%$ & $22.0 \%$ \\
$4-5$ & $20.7 \%$ & $17.1 \%$ \\
$6-9$ & $21.0 \%$ & $18.3 \%$ \\
$10-19$ & $16.0 \%$ & $13.4 \%$ \\
$20+$ & $8.3 \%$ & $3.7 \%$ \\
Age at first sex/intercourse & & $17.19(2.89)$ \\
$\quad M$ (SE) & $17.78(3.35)$ & $25,3 \%$ \\
Sex frequency (over two weeks) & $29,3 \%$ & $24,1 \%$ \\
$\quad<0.5$ times & $23,1 \%$ & $21,7 \%$ \\
$\quad<2$ times & $22,4 \%$ & $28,9 \%$ \\
$2-4$ & $25,2 \%$ & $3.60(1.17)$ \\
$4+$ & $3.71(1.08)$ & \\
Sexual satisfaction (five-point scale) & & $3.55(1.15)$ \\
$\quad M$ (SE) & $3.73(.89)$ & 90 \\
Importance of sex (five-point scale) & 925 & $22.2 \%$ \\
$M$ (SE) & & $10.0 \%$ \\
\hline$N$ (all respondents) & $20.8 \%$ & \\
\hline Experience with sexual abuse before 18 & $8.9 \%$ & \\
$\quad$ yes' & & \\
Experience with sexual abuse after 18 & & \\
$\quad$ yes' & & \\
\hline
\end{tabular}

$* p<.05, * * p<.01, * * * p<.001$

datasets. More specifically, higher numbers of sexual partners were reported in the Internet survey compared to the population survey. Since older respondents and respondents with a lower level of education are more accurately represented in the population sample and these groups report higher numbers of sexual partners, differences in sample composition might suppress differences in scores on this particular variable. Regarding 'Age of first sexual experience/intercourse' (Table 8) we found that when we did not control for sociodemographic variables, no differences were found between the datasets. However, when we did control for these factors, female SMIs in the Internet sample reported having had their first sexual experience/intercourse at an older age than female SMIs in the population sample. As respondents in the Internet sample were significantly younger than those in the population sample, this might reveal these respondents as a group who had their first sexual experience at a relatively older age. Concerning the latter findings, we should be aware that we cannot distinguish sampling or recruitment effects from mode effects.

\section{Conclusions and Discussion}

In this study we focused on the differences between two survey methods to study female SMIs. This group was studied both as a subgroup of a population survey on sexual health, 


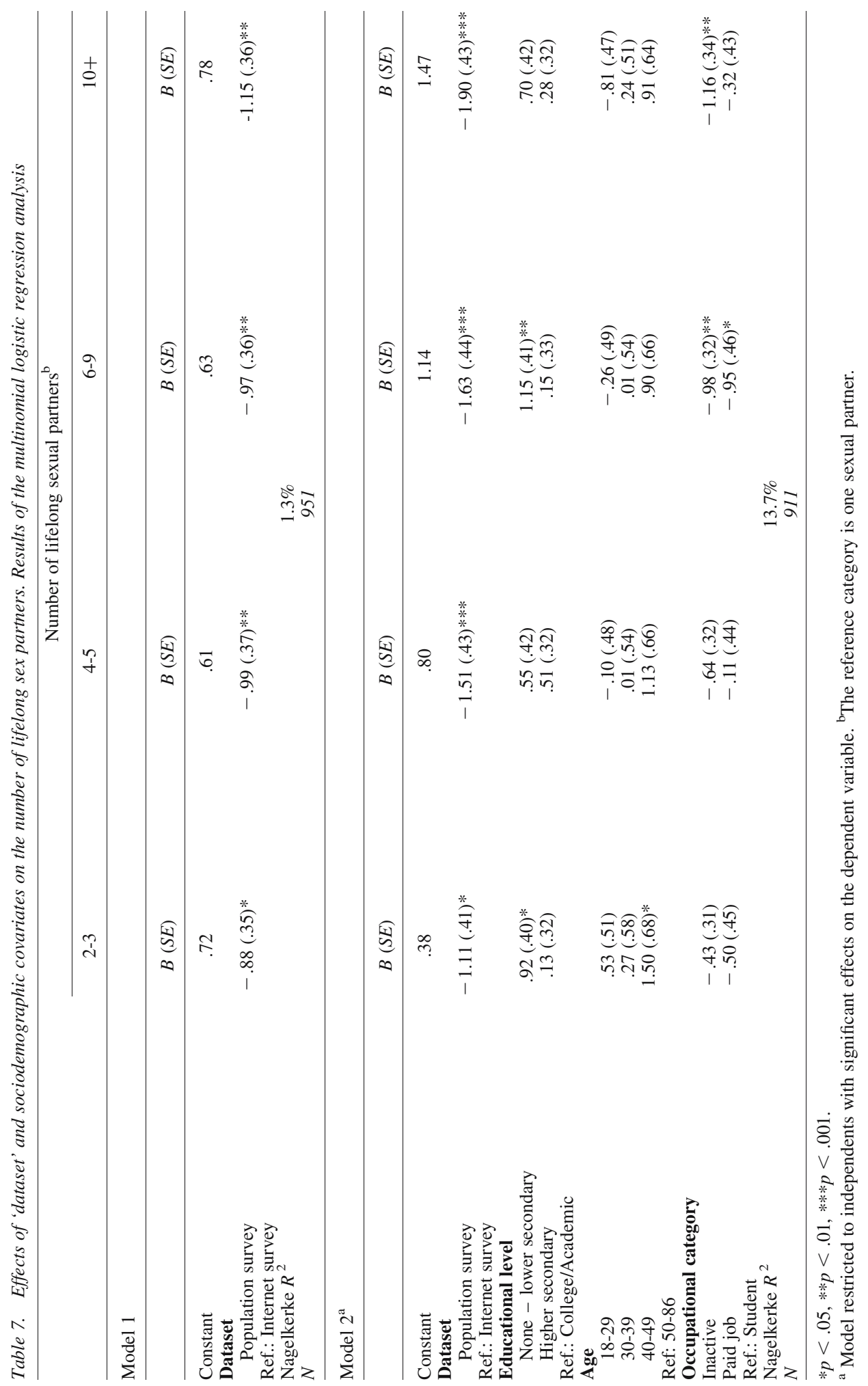


Table 8. Predictors of age of first sexual experience/intercourse

\begin{tabular}{|c|c|}
\hline & Age at first sex/intercourse \\
\hline Model 1 & $B(S E)$ \\
\hline Constant & 17.78 \\
\hline \multicolumn{2}{|l|}{ Dataset } \\
\hline $\begin{array}{c}\text { Population survey } \\
\text { (Ref.: Internet survey) }\end{array}$ & $-.42(.43)$ \\
\hline Model $2^{\mathrm{a}}$ & $B(S E)$ \\
\hline Constant & 19.79 \\
\hline \multicolumn{2}{|l|}{ Dataset } \\
\hline Population survey & $-1.24(.44)^{* *}$ \\
\hline \multicolumn{2}{|l|}{ Ref.: Internet survey } \\
\hline \multicolumn{2}{|l|}{ Educational level } \\
\hline None/primary education & $-.74(.59)$ \\
\hline Lower secondary & $-1.49(.36)^{* * *}$ \\
\hline Higher secondary & $-.20(.28)$ \\
\hline \multicolumn{2}{|l|}{ Ref.: College/Academic } \\
\hline \multicolumn{2}{|l|}{ Age } \\
\hline $18-29$ & $-2.22(.44) * * *$ \\
\hline $30-39$ & $-1.03(.46)^{*}$ \\
\hline $40-49$ & $-.62(.48)$ \\
\hline \multicolumn{2}{|l|}{ Ref: $50-86$} \\
\hline \multicolumn{2}{|l|}{ Occupational category } \\
\hline Inactive & $-.72(.28)^{*}$ \\
\hline Paid job & $.23(.39)$ \\
\hline \multicolumn{2}{|l|}{ Ref.: Student } \\
\hline$R^{2}$ & $11,6 \%$ \\
\hline$N$ & 863 \\
\hline
\end{tabular}

drawing from a population-based probability sample, and as a subgroup that was directly targeted and invited to participate in an Internet survey on sexual health. These surveys included different sampling and recruitment strategies while employing quasi-identical questionnaires and modes of administration.

Our analyses showed that, in terms of sociodemographic compositions, the samples differed in terms of age, educational level, occupation, and income. Consequently, these are the most plausible factors for explaining differences in survey outcomes, or at least for explaining differences that can be linked to the different sampling and recruitment techniques. Put differently, SMIs who are nonrandomly recruited through the Internet are a specific group. Our research, and that of many others (see e.g., Mathy et al. 2002; Claeys and Spee 2005), shows that these respondents often have high levels of education and are younger. However, efforts made to evaluate SMI populations are always imperfect since the population is by nature hard-to-reach, and the solutions to address this are lacking. 
Of course, this does not mean that all efforts should be stopped. On the contrary, the distinction between self-identifying SMIs and WSW has become especially relevant from a sexual health perspective (Loosier and Dittus 2010; McCabe et al. 2012; Mercer et al. 2007).

We found that our Internet sample generated a smaller proportion of WSW compared to our population sample. This is not very surprising, as we can expect that a targeted recruitment strategy will at least partly appeal more to SMIs who identify as gay, lesbian, or bisexual (see e.g., Fernee and Keuzenkamp 2011). However, in absolute numbers there were more WSW in the Internet sample $(N=76)$ than in the population sample $(N=53)$. These WSW appeared to be younger and more likely to still be attending school than the WSW in the population sample (results not included in this article). This subgroup is therefore probably not representative of the SMI population.

Looking at specific sexual health measures, our comparison showed no differences on the scores for six of the seven variables. The datasets did differ on the number of reported lifelong sex partners or, when sociodemographic variables were controlled for, on the reported age of first sexual experience. Due to the paucity of literature on the topic of Internet use and sexual health in female SMIs, these findings are difficult to interpret. Moreover, it is hard to really distinguish sampling or recruitment (including self-selection) effects from mode effects. However, we would like to propose several solutions to address these issues, such as combining sampling methods via propensity score matching (PSM), using fully randomized studies to learn about interviewer effects, and using calibration methods.

Firstly, combining the two sampling methods through PSM, based on the most distinguishing features (e.g., age and socioeconomic status), could be one part of the solution. Including additional questions in both questionnaires or assessing other survey features could also make PSM possible. For instance, within the population survey questionnaire, questions about Internet access, the frequency and modalities of Internet use and an assessment of the respondents' willingness and the likelihood of participation in an Internet survey could generate important information about the mechanisms of selfselection in online research, sample overlap, and (non)response in Internet surveys.

Secondly, to compare CASI-on-the-web versus CASI in the presence of an interviewer, a fully randomized study could possibly help to isolate potential interviewer effects. For instance, we could construct a study where a randomly selected part of the probability sample (drawn from the National Register and using the same contact procedures) could be assigned to the Internet survey and the other part could be assigned to the CASI-withinterviewer mode. Another possibility would be that a targeted sampling design could be followed by one of these two modes of administration (CASI-on-the-web versus CASIwith-interviewer).

We also recommend further study of how different recruitment channels lead to different respondent profiles. As diversity is more important than representativeness in Internet samples, research needs to explore how different channels (Facebook, mailings, social networks, and so on) contribute to sample diversity. As our elaborate methodological description shows, we made a great effort to increase the diversity of our sample by using a variety of recruitment channels. This diversity is important as SMIs with high levels of involvement in the gay community have different psychological and risk profiles than those not involved (Ramirez-Valles 2002). Participation of SMIs within LGB venues could have characteristics that correlate with the main variables of interest in 
the study (Meyer and Wilson 2009). Social network media might offer new opportunities to recruit and interact with potential research participants, especially in times where response rates are dropping (Groves 2006). Hard-to-reach populations such as SMIs might be especially accessible in these new virtual venues as they make it easier for stigmatized individuals to share delicate information. Of course, although this diversity in online samples is important and allows the generation of data on specific subpopulations (e.g., bisexuals, elderly SMIs), it does still not generate representative samples.

Thirdly, in our study the low numbers of male SMIs in the population sample made reliable deductions impossible for this group. Even when larger samples are available, a comparison within an SMI population (e.g., WSW versus lesbian and bisexual women) is often difficult, due to lack of power. Therefore, one could combine the strengths of both survey methods, including unique sampling and recruitment strategies and different modes of administration. Propensity matching could be used to combine the strengths of both sampling methods. Another possibility would be to weigh survey measures coming from an Internet survey using figures acquired from a reliable, highly representative population sample that includes a sufficient number of SMIs (i.e., adopting a calibration approach). Preferably, these weightings should not only incorporate a range of relevant sociodemographic variables, but also diverse indicators and dimensions of sexual orientation and other relevant features such as items on Internet access and use. One high-quality 'baseline' population study could be sufficient to supply the necessary data for many future online surveys on a variety of topics in SMI or other minority populations (e.g., ethnic minority populations). However, this would acquire large population-based samples. Estimating that $5 \%$ to $10 \%$ of a population belongs to a sexual minority, at least 4,000 respondents would be needed to obtain the minimum of 100-150 female and 100-150 male SMIs required to enable the extraction of reliable sampling sizes. This is not always possible in small communities or when limited resources are available. Also, further research has yet to prove that these adjusted and weighted samples are reliable.

To conclude, traditional methods that generate representative samples offer opportunities to gather data on the 'real' hidden SMI population (i.e., those individuals who are not inclined to participate in Web surveys). On the other hand, targeted sampling when combined with an Internet survey has some advantages, such as lower cost and the ability to generate large samples, especially in relatively small communities. The application of Internet surveys, which have often been used to reach SMIs (Dewaele et al. 2011; Aerts et al. 2012; Grov et al. 2006), could be significantly improved by combining sampling methods via propensity score matching (PSM), by further research that reveals the effect of the presence of an interviewer, and by using calibration methods. However, to gather reliable data on SMIs and to avoid self-selection bias, a population-based probability sample (of at least 4,000 respondents) remains the gold standard.

\section{References}

Aerts, S., Van Houtte, M., Dewaele, A., Cox, N., and Vincke, J. (2012). Sense of Belonging in Secondary Schools: A Survey of LGB and Heterosexual Students in Flanders. Journal of Homosexuality, 59, 90-113. DOI: http://www.dx.doi.org/10.1080/ 00918369.2012.638548 
Bajos, N. and Bozon, M. (2008). Enquête sur la sexualité en France. Paris: Éditions La Découverte.

Bakker, F., de Graaf, H., de Haas, S., Kedde, H., Kruijer, H., and Wijsen, C. (2009). Seksuele gezondheid in Nederland 2009. Utrecht: Ruthers Nisso Groep. Available at: http://www.rutgerswpf.nl/sites/default/files/Seksuele\%20Gezondheid\%20in\%20 Nederland\%202009.pdf (accessed March 30, 2014)

Bauermeister, J., Pingel, E., Zimmerman, M., Couper, M., Carballo-Diéguez, A., and Strecher, V.J. (2012). Data Quality in Web-Based HIV/AIDS Research: Handling Invalid and Suspicious data. Field Methods, 24, 272-291. DOI: http://www.dx.doi.org/ 10.1177/1525822X12443097

Best, S.J. and Krueger, B.S. (2004). Internet Data Collection. Thousand Oaks, CA: Sage. Buysse, A., Caen, M., Dewaele, A., Enzlin, P., Lievens, J., T’Sjoen, G., Van Houtte, M., and Vermeersch, H (2013). Seksuele Gezondheid in Vlaanderen. Ghent: Academia Press.

Claeys, L. and Spee, S. (2005). Een Virtuele Illusie of Reële Kansen? - Gender in de Netwerkmaatschappij. Antwerp: Steunpunt Gelijkekansenbeleid, University of Antwerp/University of Hasselt. Available at: http://www.steunpuntgelijkekansen.be/ wp-content/uploads/18.-Een-virtuele-illusie-of-reele-kansen-L.-Claeys.pdf (accessed March 30, 2014)

Couper, M.P. (2000). Web Surveys: A Review of Issues and Approaches. Public Opinion Quarterly, 64, 464-494. DOI: http://dx.doi.org/10.1086/318641

Couper, M.P. (2008). Designing Effective Web Surveys. Cambridge: Cambridge University Press.

de Leeuw, E.D. (2005). To Mix or not to Mix Data Collection Modes in Surveys. Journal of Official Statistics, 21, 233-255.

Denscombe, M. (2006). Web-Based Questionnaires and the Mode Effect - An Evaluation Based on Completion Rates and Data Contents of Near-Identical Questionnaires Delivered in Different Modes. Social Science Computer Review, 24, 246-254. DOI: http://www.dx.doi.org/10.1177/0894439305284522

Dewaele, A., Cox, N., van den Berghe, W., and Vincke, J. (2011). Families of Choice? Exploring the Supportive Networks of Lesbians, Gay Men and Bisexuals. Journal of Applied Social Psychology, 41, 312-331. DOI: http://www.dx.doi.org/10.1111/j. 1559-1816.2010.00715.x

Dillman, D.A. (1978). Mail and Telephone Surveys: The Total Design Method. New York: Wiley.

Dillman, D.A. (2000). Mail and Internet Surveys: The Tailored Design Method. London: Wiley.

Edelman, M. (1993). Understanding the Gay and Lesbian Vote in 1992. Public Perspective, 4, 32-33.

Evans, J.R. and Mathur, A. (2005). The Value of Online Surveys. Internet Research, 15, 195-219.

Fernee, H. and Keuzenkamp, S. (2011). Selectiviteit van de Roze Vragenlijst. Een Vergelijking met Paneldata (paper presented at Sociology Day on May 26, 2011, Den Haque). Available at: http://www.google.be/url?sa=t\&rct=j\&q=\&esrc $=\mathrm{s} \&$ source $=$ web $\& c d=1 \&$ ved $=0 \mathrm{CC} 4 \mathrm{QFjAA} \& u r l=\mathrm{http} \% 3 \mathrm{~A} \% 2 \mathrm{~F} \% 2 \mathrm{Fwww} \cdot \mathrm{scp} \cdot \mathrm{nl} \% 2 \mathrm{Fd}$ 
sresource\%3Ftype\%3Dpdf\%26objectid\%3Ddefault\%3A29290\%26versionid\%3D\% 26subobjectname\%3D\&ei=9eg3U4DgMsWqhAeQg4CwAw\&usg=AFQjCNG6pS 0WGCZ1_Hf4RaSfq8ILoHQYAQ\&bvm=bv.63808443,d.ZG4. (accessed March 30, 2014)

Gronow, J., Haavio-Mannila, E., Kivinen, M., Lonkila, M., and Rotkirch, A. (1997). Cultural Inertia and Social Change in Russia. Helsinki: University of Helsinki, Department of Sociology.

Grov, C., Bimbi, D.S., Nanín, J.E., and Parsons, J.T. (2006). Ethnicity, Gender, and Generational Factors Associated with the Coming-Out Process Among Gay, Lesbian, and Bisexual Individuals. Journal of Sex Research, 43, 115-121.

Groves, R.M. (2006). Non-Response Rates and Non-Response Bias in Household Surveys. Public Opinion Quarterly, 70, 646-675. DOI: http://www.dx.doi.org/10.1093/poq/ nfl033

Haavio-Mannila, E. and Kontula, O. (2001). Seksin Trendit Meillä ja Naapureissa. Helsinki: WSOY.

Heerwegh, D. (2001). Surveyonderzoek Middels het Internet: Een exploratie van het Terrein. Leuven: Katholieke Universiteit Leuven, Departement Sociologie, Afdeling voor dataverzameling en analyse. Available at: https://perswww.kuleuven. be/ u0034437/public/Files/Survey-onderzoek\%20middels\%20het\%20Internet.pdf (accessed March 30, 2014)

Kerker, B.D., Mostashari, F., and Thorpe, L. (2006). Health Care Access and Utilization Among Women Who Have Sex With Women: Sexual Behavior and Identity. Journal of Urban Health, 83, 970-979. DOI: http://www.dx.doi.org/10.1007/s11524-006-9096-8

Koch, S.N. and Emrey, J.A. (2001). The Internet and Opinion Measurement: Surveying Marginalized Populations. Social Science Quarterly, 82, 131-138. DOI: http://www. dx.doi.org/10.1111/0038-4941.00012

Kreuter, F., Presser, S., and Tourangeau, R. (2008). Social Desirability Bias in CATI, IVR, and Web Surveys: The Effects of Mode and Question Sensitivity. Public Opinion Quarterly, 72, 847-865. DOI: http://www.dx.doi.org/10.1093/poq/nfn063

Laumann, E., Gagnon, J.H., Michael, R.T., and Michaels, S. (1994). The Social Organization of Sexuality: Sexual Practices in the United States. Chicago: University of Chicago Press.

Lievens, J. and Waege, H. (2009). Participatie in Vlaanderen. Basisgegevens van de participatiesurvey. Leuven: Acco.

Loosier, P.S. and Dittus, P.J. (2010). Group Differences in Risk Across Three Domains Using an Expanded Measure of Sexual Orientation. Journal of Primary Prevention, 31, 261-272. DOI: http://www.dx.doi.org/ 10.1007/s10935-010-0228-2

Mathy, R.M., Schillace, M., Coleman, S.M., and Berquist, B.E. (2002). Methodological Rigor With Internet Samples: New Ways to Reach Underrepresented Populations. CyberPsychology and Behavior, 5, 253-266.

McCabe, S.E., Hughes, T.L., Bostwick, W., Morales, M., and Boyd, C.J. (2012). Measurement of Sexual Identity in Surveys: Implications for Substance Abuse Research. Archives of Sexual Behavior, 41, 649-657. DOI: http://www.dx.doi.org/10. 1007/s10508-011-9768-7 
Mercer, C.H., Bailey, J.V., Johnson, A.M., Erens, B., Wellings, K., Fenton, K.A., and Copas, A.J. (2007). Women Who Report Having Sex With Women: British National Probability Data on Prevalence, Sexual Behaviors, and Health Outcomes. American Journal of Public Health, 97, 1126-1133. DOI: http://www.dx.doi.org/10.2105/AJPH. 2006.086439

Meyer, I.H. and Wilson, P.A. (2009). Sampling Lesbian, Gay, and Bisexual Populations. Journal of Counseling Psychology, 56, 23-31. DOI: http://www.dx.doi.org/10.1037/ a0014587

Ramirez-Valles, J. (2002). The Protective Effects of Community Involvement for HIV Risk Behavior: A Conceptual Framework. Health Education Research, 17, 389-403.

Raymond, H.F., Rebchook, G., Curotto, A., Vaudrey, J., Amsden, M., Levine, D., and McFarland, W. (2010). Comparing Internet-Based and Venue-Based Methods to Sample MSM in the San Francisco Bay Area. Aids and Behavior, 14, 218-224. DOI: http://www.dx.doi.org/10.1007/s10461-009-9521-6

Roberts, A.L., Austin, S.B., Corliss, H.L., Vandermorris, A.K., and Koenen, K.C. (2010). Pervasive Trauma Exposure Among US Sexual Orientation Minority Adults and Risk of Posttraumatic Stress Disorder. American Journal of Public Health, 100, 2433-2441. DOI: http://www.dx.doi.org/10.2105/AJPH.2009.168971

Rothblum, E. (2007). From Science Fiction to Computer-Generated Technology: Sampling Lesbian, Gay, and Bisexual Individuals. In The Health of Sexual Minorities: Public Health Perspectives on Lesbian, Gay, Bisexual and Transgender Populations, I.H. Meyer and M.E. Northridge (eds). New York: Springer, 441-454.

Schillewaert, N. and Meulemeester, P. (2005). Comparing Response Distributions of Offline and Online Data Collection Methods. International Journal of Market Research, 47, $163-178$.

Schonlau, M., van Soest, A., Kapteyn, A., and Couper, M. (2009). Selection Bias in Web-Surveys and the Use of Propensity Scores. Sociological Methods and Research, 37, 291-318.

Schwarcz, S., Spindler, H., Scheer, S., Valleroy, L., and Lansky, A. (2007). Assessing Representativeness of Sampling Methods for Reaching Men Who Have Sex With Men: A Direct Comparison of Results Obtained from Convenience and Probability Samples. AIDS and Behavior, 11, 596-602.

Silenzio, V.M.B., Duberstein, P.R., Tang, W., Lu, N., Tu, X., and Homan, C.M. (2009). Connecting the Invisible Dots: Reaching Lesbian, Gay, and Bisexual Adolescents and Young Adults at Risk for Suicide Through Online Social Networks. Social Science and Medicine, 69, 469-474. DOI: http://www.dx.doi.org/10.1016/j.socscimed.2009.05.029 Tourangeau, R., Couper, M.P., and Steiger, D.M. (2003). Humanizing Self-Administered Surveys: Experiments on Social Presence in Web and IVR Surveys: Experiments on Social Presence in Web and IVR Surveys. Computers in Human Behavior, 19, 1-24. DOI: http://www.dx.doi.org/10.1016/S0747-5632(02)00032-8

Van Kesteren, N.M.C., Hospers, H., and Kok, G. (2007). Sexual Risk Behavior Among HIV-Positive Men Who Have Sex With Men: A Literature Review. Patient Education and Counseling, 65, 5-20.

Vincke, J. and Bleys, R. (2003). Vitale Vragen 2001. Eindrapport. Antwerp: Sensoa. 
Vincke, J. and Stevens, P. (1999). Een Beleidsgerichte Algemene Survey van Vlaamse Homoseksuele Mannen en Vrouwen-Basisrapport. Brussels: Ministerie van de Vlaamse Gemeenschap, Cel Gelijke Kansen, Universiteit Gent. Available at: http://www.psw.ugent.be/cms_global/uploads/publicaties/personal/eindrapport.pdf. (accessed March 30, 2014).

Vincke, J. and van Heeringen, K. (2004). Summer Holiday Camps for Gay and Lesbian Young Adults: An Evaluation of Their Impact on Social Support and Mental Well-Being. Journal of Homosexuality, 47, 33-46. DOI: http://www.dx.doi.org/ 10.1300/J082v47n02_02

Wright, K.B. (2005). Researching Internet-Based Populations: Advantages and Disadvantages of Online Survey Research, Online Questionnaire Authoring Software Packages, and Web Survey Services. Journal of Computer-Mediated Communication, 10, article 11. Available at: http://onlinelibrary.wiley.com/doi/10.1111/j.1083-6101. 2005.tb00259.x/full?utm_source. (accessed March 30, 2014).

Received February 2013

Revised February 2014

Accepted March 2014 